\title{
The cost-effectiveness of government actions to reduce sodium intake through salt substitutes in Vietnam
}

\author{
Colman Taylor ${ }^{1,2^{*}}$ (D), Annet C. Hoek', Irene Deltetto², Adrian Peacock², Do Thi Phuong Ha ${ }^{3}$, Michael Sieburg ${ }^{4}$, \\ Dolly Hoang ${ }^{4}$, Kathy Trieu', Laura K. Cobb ${ }^{5}$, Stephen Jan ${ }^{1}$ and Jacqui Webster ${ }^{1}$
}

\begin{abstract}
Background: Dietary sodium reduction is recommended to reduce the burden of cardiovascular disease. In Vietnam food products including salt, fish sauce and bot canh contribute to $\sim 70 \%$ of dietary sodium intake. Reduced sodium versions of these products can be produced by replacing some of the sodium chloride with potassium chloride. We aimed to assess the cost-effectiveness of three alternative approaches to introducing reduced sodium products onto the market with a view to lowering population sodium intake in Vietnam.
\end{abstract}

Methods: The three salt substitution strategies included voluntary, subsidised and regulatory approaches targeting salt, fish sauce and bot canh products. Costs were modelled using the WHO-CHOICE methodology. A Markov cohort model was developed to evaluate the cost-effectiveness of each strategy versus no intervention from the government perspective. The model linked each intervention strategy to assumed changes in levels of sodium intake and then to systolic blood pressure. Changes in SBP were linked to a probability of ischaemic heart disease or stroke. The model followed people over their lifetime to assess average costs and quality adjusted life years (QALYs) gained for each strategy.

Results: The voluntary salt substitution strategy was assumed to require no investment by government. Following ramp up (years 6+), the average annual costs for the subsidised and regulatory strategies were $21,808,968,902$ đ (US\$ 977,354) and 12,949,953,247 đ (US\$ 580,410) respectively. Relative to no intervention, all three salt substitution strategies were found to be cost-effective. Cost savings were driven by reductions in strokes $(32,595 ; 768,384 ; 2,366$, $480)$ and ischaemic heart disease (IHD) events $(22,830 ; 537,157 ; 1,648,590)$ for the voluntary, subsidised \& regulatory strategies, respectively. The voluntary strategy was least cost-effective ( 3445 đ US\$ $-0.15 ; 0.009$ QALYs gained) followed by the subsidised strategy ( $-43,189 ₫$ US\$ $-1.86 ; 0.022$ QALYs gained) and the regulatory strategy delivered the highest cost savings and health gains (-243,530 đ US\$ -10.49; 0.074 QALYs gained).

(Continued on next page)

\footnotetext{
* Correspondence: ctaylor@georgeinstitute.org.au

${ }^{1}$ The George Institute for Global Health, Australia University of NSW, PO Box

M201, Missenden Rd, Camperdown, NSW 2050, Australia

${ }^{2}$ Health Technology Analysts Pty Ltd, Surry Hills, Australia

Full list of author information is available at the end of the article
} 
(Continued from previous page)

Conclusion: This research shows that all three modelled salt substitution strategies would be good value for money relative to no intervention in Vietnam. The subsidised alternative would require the highest level of government investment; however the implementation costs will be exceeded by healthcare savings assuming a reasonable time horizon is considered.

Keywords: Diet, Sodium, CHD, Stroke, Cost-effectiveness, Health economics

\section{Background}

Cardiovascular disease (CVD) is one of the leading causes of non-communicable disease mortality and morbidity globally [1]. The most common causes of CVD morbidity and mortality are ischaemic heart disease (IHD) and stroke, accounting for $85 \%$ of all CVD deaths in 2016 [2,3]. Due to higher exposure to modifiable risk factors and poor access to effective health care interventions, the impact of CVD is magnified in lower income countries [1].

The direct causal relationship between dietary salt (sodium chloride) intake and blood pressure is now well established [4]. It has long been recognised that hypertension (high blood pressure) is one of the major risk factors for stroke and IHD [5, 6]. Reduction of dietary salt intake is considered an effective measure to reduce blood pressure, with the World Health Organisation (WHO) recommending the consumption of less than $5 \mathrm{~g}$ (g) of salt per day [7]. The WHO has urged its member states to take action at a population level to reduce dietary salt intake [8]. The reduction of excess dietary salt is widely recognised as one of the most cost-effective means for lowering blood pressure and preventing noncommunicable disease across the world [9-18].

With economic development and an aging population, Vietnam has undergone a transition from managing communicable diseases to now confronting a growing population suffering from non-communicable disease $[19,20]$. The WHO estimates that non-communicable diseases account for $73 \%$ of total deaths in Vietnam, of which approximately $43 \%$ are attributed to cardiovascular diseases including IHD and stroke [21]. Hypertension has been one of the primary contributors to the overall burden of disease in Vietnam during this shift. In 1960, the rate of adult hypertension in Northern Vietnam was $1 \%$ [22]. The prevalence of hypertension in Vietnam as of 2014 is estimated to be $22 \%$ among adults [21]. This has significant implications for the Vietnam Government as the main funder of healthcare.

Recent research has estimated the average salt intake in Vietnam to be $9.4 \mathrm{~g} /$ day [23], nearly double the $5 \mathrm{~g} /$ day recommended by the WHO [8]. Approximately 70\% of salt consumption currently comes from salt, fish sauce and bot canh [24]. One method of reducing sodium in these food products is the use of a salt substitute, such as potassium chloride, which has been shown to be effective at lowering blood pressure [25]. Various options exist to implement salt substitution at a population level, including leaving manufacturers to reformulate products (in a voluntary capacity) or involving Government (through subsidies or regulation). While studies conducted both globally and locally in Vietnam have found salt reduction policies and campaigns to be very cost-effective $[4,13,17,26,27]$, the cost-effectiveness of a salt substitution intervention using potassiumenriched low sodium food products, from the perspective of the Vietnam Government, remains unknown.

We aimed to assess the cost-effectiveness of reformulating three target products that make up the majority of salt intake in Vietnam with potassium chloride and therefore lowering sodium intake in Vietnam at a population level. In doing so, we investigate the cost of three potential salt substitution strategies and a range of effectiveness estimates, to estimate the cost-effectiveness of salt substitution at a population level in Vietnam.

\section{Methodology}

Three salt substitution strategies using potassium chloride were investigated to reduce sodium in three target products in Vietnam (salt, fish sauce and bot canh [a popular seasoning in Vietnam]). All strategies were detailed and costed both in terms of program costs and salt reformulation costs. Population impact of the strategies was also estimated based on the proportion of products reformulated and the adoption of the low salt products by consumers. Inputs including program costs, reformulation costs, program impact and other variables were then modelled to understand the cost-effectiveness of the salt substitution strategies (Fig. 1).

\section{Definition of salt substitution strategies}

The three salt substitution strategies included voluntary, subsidised and regulatory approaches as proxies for low, medium and high impact interventions respectively (see Tables and figures Table 1). These would lead to the consumers replacing a proportion of the target product consumption with potassium-enriched, low sodium options.

Briefly, the voluntary scenario assumes companies will voluntarily provide new reformulated low sodium 


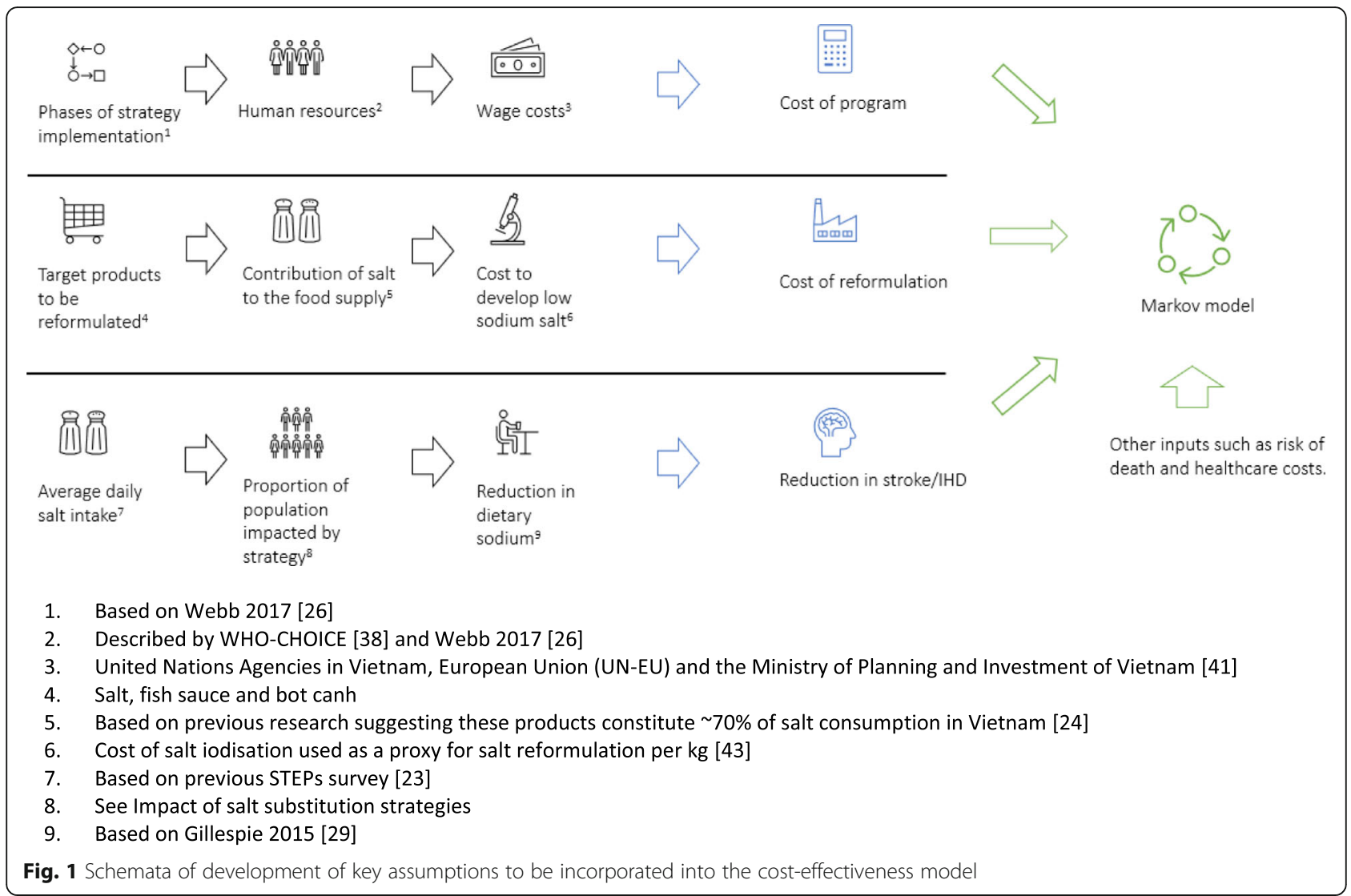

Table 1 Details of salt substitution strategies including estimated uptake, cost, resources and coverage

\begin{tabular}{|c|c|c|c|}
\hline Parameter & Voluntary & Subsidised & Regulatory \\
\hline Description & $\begin{array}{l}\text { Companies that make target } \\
\text { products* voluntarily introduce new } \\
\text { products low sodium products with } \\
\text { potassium chloride. }\end{array}$ & $\begin{array}{l}\text { Government subsidisation of potassium } \\
\text { chloride to equal cost of salt - allowing } \\
\text { manufacturers to use potassium chloride in } \\
\text { target products* as a salt substitute. }\end{array}$ & $\begin{array}{l}\text { Legislation requiring all target } \\
\text { products* to have a portion of their } \\
\text { sodium content replaced by } \\
\text { potassium chloride. }\end{array}$ \\
\hline Industry uptake & Assumed to be low & Assumed to be moderate & Assumed to be high \\
\hline Cost & $\begin{array}{l}\text { Extra cost of low sodium products is } \\
\text { passed onto consumers }\end{array}$ & $\begin{array}{l}\text { Borne by Government (for subsidy). } \\
\text { Manufacturers are assumed to produce and } \\
\text { sell low salt products at a similar price to } \\
\text { regular products and therefore no extra cost is } \\
\text { passed onto consumers }\end{array}$ & $\begin{array}{l}\text { Borne by Government (for legislation) } \\
\text { and manufacturers (for production). } \\
\text { Low salt products are assumed to be } \\
\text { sold at a similar price }\end{array}$ \\
\hline $\begin{array}{l}\text { Proportion of target } \\
\text { products* } \\
\text { reformulated with } \\
\text { potassium chloride }\end{array}$ & $30 \%$ & $50 \%$ & $100 \%$ \\
\hline $\begin{array}{l}\text { Proportion of people } \\
\text { choosing } \\
\text { reformulated target } \\
\text { products* }\end{array}$ & $5 \%$ & $44 \%$ & $100 \%$ \\
\hline $\begin{array}{l}\text { Media and } \\
\text { communications } \\
\text { campaign }\end{array}$ & Not included & Included & Not included \\
\hline
\end{tabular}


products. This requires no government support (low cost) but is assumed to have a lower uptake by consumers and therefore lower impact on population level sodium consumption (see Impact of salt substitution strategies). Both the subsidised and regulatory scenarios require government intervention to either incentivise or mandate food companies to reformulate existing target products with potassium chloride. In the subsidised scenario, the Vietnam Government is assumed to fund reformulation of a proportion of the target products, whereas in the regulatory scenario, the Vietnam Government will mandate that all target products are reformulated with potassium chloride.

As voluntary strategy assumes that initiatives are left to the market and food industry with no involvement or coordination from Government, no coordinated mass media campaign was included. In contrast, the subsidised strategy included a communications and media campaign to drive uptake, as stakeholder research with manufacturers indicated this would be essential to justify $R \& D$ costs [28]. Finally, the regulatory strategy included no media campaign as compliance was assured through regulation. This is consistent with a similar scenario modelled for China [4].

\section{Calculation of impact of salt substitution strategies}

The decrease in sodium chloride content in food products due to substitution with potassium chloride for each modelled strategy is based on the coverage, efficacy and impact formula described by Gillespie et al. [29]. The method takes into consideration the proportion of daily sodium intake from the low sodium target products, the effect of reformulation, the proportion of targeted products to be reformulated and the expected uptake of the low sodium products. This provides an estimated daily reduction in sodium consumption which can be applied to the average daily sodium intake (Table 2).

Recognising the uncertainty of these assumptions and their impact on the model result, a threshold analysis was conducted (see Sensitivity and Threshold Analysis).
The model does not consider any beneficial or harmful effects stemming from potassium chloride.

All strategies started from the average salt intake for the Vietnamese population, which was estimated to be $9.40 \mathrm{~g} /$ day [23]. The salt reduction in target products due to reformulation was consistent throughout the strategies (60\% based on previous research [30]).

For the voluntary strategy, it was assumed that manufacturers would choose to reformulate $30 \%$ of the target products (salt, fish sauce and bot canh). However due to reformulation costs being passed onto consumers, it was assumed uptake of these products would be low (5\%). To ascertain the impact of this strategy, the daily salt intake $(9.4 \mathrm{~g})$ was multiplied by the following variables per Gillespie et al. [29]: the proportion of dietary salt from the target products $(70 \%)$; the salt reduction in target products due to reformulation (60\%); the proportion of products reformulated (30\%); the product uptake (5\%). This resulted in a modest total dietary salt reduction of $0.06 \mathrm{~g} /$ day (Table 2).

In contrast, the regulatory strategy was assumed to have maximum uptake as legislation would guarantee all target products are reformulated with potassium chloride, which would lead to $100 \%$ of people having to use the reformulated products. The latter assumption takes into account the high adoption rate $(>90 \%)$ seen in the Vietnam National Iodisation Program [32]. The impact of the regulatory strategy on dietary salt intake was calculated by multiplying the baseline daily salt intake ( 9.4 $\mathrm{g} /$ day) by the following variables: the proportion of dietary salt from the target products $(70 \%)$; the salt reduction in target products due to reformulation (60\%); the proportion of products reformulated (100\%); the product uptake (100\%). This resulted in a total dietary salt reduction of $3.95 \mathrm{~g} /$ day (Table 2).

For the subsidised intervention, it was assumed $50 \%$ of the target products would be reformulated with potassium chloride. It was assumed a government subsidy would be used to supply potassium chloride at the same price or cheaper than sodium chloride. This would lead to reformulated products being sold at the same price or

Table 2 Details of assumptions for each salt substitute strategy to calculate impact on average dietary salt intake, Vietnam

\begin{tabular}{lllll}
\hline Parameter & Voluntary & Subsidised & Regulatory & Source \\
\hline Average daily salt intake (A) & $9.4 \mathrm{~g} /$ day & $9.4 \mathrm{~g} /$ day & $9.4 \mathrm{~g} /$ day & {$[23]$} \\
Proportion of salt from target products (B) & $70 \%$ & $70 \%$ & $70 \%$ & {$[24]$} \\
Sodium reduction in target products due to reformulation & $60 \%$ & $60 \%$ & $60 \%$ & {$[30]$} \\
Proportion of target products reformulated with potassium chloride (C) & $30 \%$ & $50 \%$ & $100 \%$ & Assumptions \\
Proportion of people choosing reformulated target products (D) & $5 \%$ & $44 \%$ & $100 \%$ & {$[31]$} \\
Dietary salt reduction due to reformulation (E) & $0.058 \mathrm{~g} /$ day & $0.865 \mathrm{~g} /$ day & $3.95 \mathrm{~g} /$ day & $\mathrm{A} \times$ X B CX D Gillespie 2015 [29] \\
Full effect of strategy on average daily salt intake & $9.34 \mathrm{~g} /$ day & $8.53 \mathrm{~g} /$ day & $5.45 \mathrm{~g} /$ day & A - E \\
\hline
\end{tabular}

An additional $5 \%$ reduction from baseline was added to the subsidised intervention to reflect the additional benefit of a communications intervention to reduce salt intake in Vietnam; target products include salt, fish sauce, bot canh 
cheaper than regular products. Product uptake of the reformulated products was based on a Vietnamese population survey that found approximately $44 \%$ of respondents would limit adding salt or sauces when cooking when given the option [31]. Furthermore, the media and health promotion campaign accompanying the subsidised programme is expected to have an additive effect on the intake of high-sodium products and is reflected as an extra 5\% reduction from baseline [13].

The impact of the subsidised strategy on dietary salt intake was calculated by multiplying the baseline daily salt intake $(9.4 \mathrm{~g} /$ day) by the following variables: the proportion of dietary salt from the target products (70\%); the salt reduction in target products due to reformulation (60\%); the proportion of products reformulated (50\%); the product uptake (44\%). This resulted in a total dietary salt reduction of $0.87 \mathrm{~g} /$ day (Table 2 ).

\section{Assumptions for strategy implementation}

To reflect the real-world planning and management of a population health intervention, each salt substitution strategy included progressive phases of implementation, modelled on Webb 2017 [26]. Specifically, the first phase includes 2 years of project management, training and meetings, advocacy and law enforcement prior to deploying the programme. These years are dedicated to the planning and development of the intervention and therefore no health effects are assumed to take place. Following this stage, the voluntary and subsidised strategy included a partial implementation phase, resulting in $50 \%$ of the total salt reduction effect of each respective strategy, to account for progressive uptake. The regulatory strategy assumes that from year three the total effect of the programme would be realised, as once legislation is implemented the programme should be $100 \%$ effective (leveraging experience from the Vietnam National Iodisation Program [32]). From years six onwards, all programmes are assumed to be at full implementation.

\section{Cost-effectiveness model structure and perspective}

A Markov cohort model was developed in TreeAge Pro based on approaches adopted in previous publications $[13,17,26]$. The model included four health states, namely healthy, post-stroke, post-IHD and death. Annual transitions captured the incidence of stroke and IHD events, mortality due to IHD or stoke events and natural mortality.

The model starts with people aged 30 years being assigned to live normally in the current environment (no intervention), or alternately, live with one of three salt substitution strategies (voluntary, subsidised or regulatory). A base case age of 30 years was selected as being representative of the median age of the Vietnam population and as it had been used previously to assess cost-effectiveness of salt reduction in Vietnam [13]. At the beginning of the model, the average SBP is calculated according to the Vietnamese population characteristics [13, 33]. The model links sodium intake to SBP based on the linear regression model published by Law et al. 1991 [34]. Secondly, SBP is linked to the probability of IHD or stroke based on Cobiac et al. 2012 [17].

Patients that experience a stroke or IHD event either die as a result of the event or progress to a "post event" health state. In the post-stroke health state, patients have an increased mortality risk compared to the healthy cohort for the lifetime of the model, whereas in the postIHD cohort there is an increased mortality risk for 3 years post event, after which mortality reverts to the natural mortality risk of that age (see input parameters). As the model has a yearly cycle length, the acute phase (initial, short-term event) for IHD and stroke is captured in a state transition, and the chronic phase (post event, long term) of the disease is captured in the respective health states. Patients cannot transition from the poststroke or post-IHD state to the healthy state, and conservatively it was assumed patients cannot experience more than one stroke or IHD event.

The time horizon of the economic model spans the lifetime of the Vietnamese population (capped at 100 years of age). A lifetime horizon (which follows a cohort from age 30 until death) was used to fully capture the benefits and costs associated with the salt substitution strategy. The model uses a discount rate of $3 \%$ for both benefits and costs; rates of 0 and 5\% were used in sensitivity analysis. Given the aims of the study, this population wide model evaluates each scenario from a Vietnam Government perspective and excludes costs borne by industry or individuals.

\section{Cost-effectiveness model input parameters}

A summary of key model inputs is presented in Table 3.

\section{Clinical events and epidemiology}

Normative data for blood pressure and the incidence of stroke and IHD were sourced from Ha 2011 [13] (see Supplementary Table 1 and 2). This paper provided the most applicable data characterising the relationship between blood pressure and incidence of IHD/stroke for the Vietnamese population. The impact of sodium intake on blood pressure was estimated based on published research by Law 1991 [34], which aligns with previous economic evaluations. The relationship between blood pressure and stroke/IHD was calculated based on the percentage relative risk reduction of stroke $(6.3 \%$ per $1 \%$ SBP reduction) and IHD (3.4\% per 1\% SBP reduction) as published by Cobiac 2012 [17]. The resulting relative risk reduction for each sodium reduction program is 
Table 3 List of inputs and sources used in cost-effectiveness model, Vietnam

\begin{tabular}{|c|c|}
\hline Variable name & Input \\
\hline \multicolumn{2}{|l|}{ Clinical events and epidemiology } \\
\hline Blood pressure & $\begin{array}{l}\text { See Supplementary Table } 1 \text { Supplementary } \\
\text { Material }\end{array}$ \\
\hline Stroke incidence & $\begin{array}{l}\text { See Supplementary Table } 2 \text { Supplementary } \\
\text { Material }\end{array}$ \\
\hline $\begin{array}{l}\text { Relative risk of stroke with } \\
\text { change in SBP }\end{array}$ & $\begin{array}{l}\text { See Supplementary Table } 3 \text { Supplementary } \\
\text { Material }\end{array}$ \\
\hline IHD incidence & $\begin{array}{l}\text { See Supplementary Table } 2 \text { Supplementary } \\
\text { Material }\end{array}$ \\
\hline $\begin{array}{l}\text { Relative risk of IHD with change } \\
\text { in SBP }\end{array}$ & $\begin{array}{l}\text { See Supplementary Table } 4 \text { Supplementary } \\
\text { Material }\end{array}$ \\
\hline Mortality & Vietnam life tables \\
\hline Mortality following stroke event & $37 \%$ \\
\hline Long term stroke mortality risk & $\begin{array}{l}\text { Year 1: } 3.33 \\
\text { Year 2: } 2.85 \\
\text { Year 3: } 3.44 \\
\text { Year 4: } 2.84 \\
\text { Year 5+: } 1.56\end{array}$ \\
\hline Mortality of IHD event & Age specific mortality risk \\
\hline Long term IHD mortality & $\begin{array}{l}\text { Year 1: } 18.7 \% \\
\text { Year 2: } 25.0 \% \\
\text { Year 3: } 39.2 \% \\
\text { Year 4+: Revert back to regular population } \\
\text { mortality }\end{array}$ \\
\hline
\end{tabular}

Resource use and programme costs reported in (USD)

Cost of lowering sodium

1791 (US\$ 0.08)

content by potassium-enriched salt

substitutes per capita

Personnel Costs for policy implementation and management

Human resource requirements for policy implementation and management

\section{Healthcare costs}

Percent of healthcare costs paid 54\% by the Government

\section{Cost of stroke event to}

$$
\text { 13,325,677 (US\$ 574.12) }
$$
Government

Long term cost of stroke to

0
Project coordinator, manager, chief accountant, technical specialist etc.: $511,526,874$ (US\$ 22,039) per year Project administrative assistant/secretary, accountant, interpreter, translator: 295,489,873 (US\$ 12,730.88) per year

Clerk, Driver, Auxiliary Staff, Messenger, Cleaner: 155,828,979 (US\$ 6714) per year Per diem daily subsistence allowance: 4,015,413 (US\$ 173.00)

Webb 2017 eTable2

\section{Source/Description}

Calculated based on Ha 2011 baseline blood pressure. Reduction in SBP for each intervention was calculated from the reduction of sodium intake with a linear regression using the Law 1991 SBP with no sodium in the diet as reference [13]

Ha 2011 [13]

Cobiac 2012 and intervention specific change in blood pressure from baseline. Each 1\% decrease in SBP equals a $6.3 \%$ risk reduction for stroke [17]

Ha 2011 [13]

Cobiac 2012 and intervention specific change in blood pressure from baseline. Each 1\% decrease in SBP equals a $3.4 \%$ risk reduction for IHD [17]

World Health Organisation and Global Health Observatory; age and gender specific [35]

Tirschwell 2012 [36]

Kiyohara 2003 [37]. Relative risk of patients with history of stroke compared to healthy controls. Model assumes patients have elevated risk of mortality (1.56x higher) compared to "healthy" population

Southeast Asian NCD impact module dataset through the WHO-CHOICE OneHealth tool

Tang 2007 [38]. Model assumes that after Year 3 patients have same mortality risk as rest of "healthy" population

Calculated as the cost of a sodium reduction Government subsidy included in the subsidised scenario. Based on:- 534, 798 t of salt produced each year [39]- 70\% of salt is in cooking salt, fish sauce and bot canh of which $50 \%$ of sodium varieties [24]- US\$0.04 to develop $1 \mathrm{~kg}$ of low sodium salt [40]

UN-EU 2015 human resource costs inflated to 2019 US\$ and converted to [41].Per diem costs from the International Civil Service Commission [42]

Webb 2017 [26]

Local expert opinion; WHO 2018 [43]

Khiaocharoen 2012 (one off event cost) [44]

Nguyen 2016 identifies stroke patients are cared for at home by family members [45] 
Table 3 List of inputs and sources used in cost-effectiveness model, Vietnam (Continued)

\begin{tabular}{|c|c|c|}
\hline Variable name & Input & Source/Description \\
\hline $\begin{array}{l}\text { Cost of IHD event to } \\
\text { Government }\end{array}$ & $17,297,679 \quad$ (US\$ 745.25) & Nguyen 2016 (one off event cost) [45] \\
\hline $\begin{array}{l}\text { Long term cost of IHD to } \\
\text { Government }\end{array}$ & (US\$ 15.89) & $\begin{array}{l}\text { Nguyen } 2016 \text { recurring yearly cost for the lifetime of the } \\
\text { patient [45] }\end{array}$ \\
\hline \multicolumn{3}{|l|}{ Quality of life } \\
\hline Healthy utility (SBP < 130) & Male: 0.734Female: 0.712 & Nguyen 2015 [46] \\
\hline $\begin{array}{l}\text { Stage } 1 \text { hypertension utility (SBP } \\
>130 \text { and < 140) }\end{array}$ & Male 0.726Female: 0.705 & Nguyen 2015 [46] \\
\hline Stroke event disutility & -0.312 & GBD 2010 [47] \\
\hline Long term post-stroke utility & Year 1: 0.66Year 2+: 0.68 & Luengo-Fernandez 2013 [48] \\
\hline IHD event disutility & -0.186 & GBD 2010 [47] \\
\hline Long term post-IHD utility & $\mathrm{OR}=-0.004$ & $\begin{array}{l}\text { Nguyen } 2015 \text { odds ratio of patients who had a history of } \\
\text { experiencing a cerebrovascular event compared to those } \\
\text { without event. Applied to life of patient [46] }\end{array}$ \\
\hline
\end{tabular}

Abbreviations: IHD ischaemic heart disease, GBD Global Burden of Disease study, SBP systolic blood pressure

provided in the Supplementary Material (see Supplementary Table 3 and 4).

At any point in the model, patients are assumed to be at risk of death. This represents the probability that a person of a specific age will die before their next birthday. All-cause mortality was sourced from the Global Health Observatory data repository Vietnam life tables, stratified by age and sex [35].

The incidence of mortality following stroke was sourced from Trishwell 2012 [36] and Kiyohara 2003 [37]. The former provided short-term mortality following the event (estimated to be 37\%) the latter provided the long term risk of mortality relative to the general population, stratified by year. The risk of mortality following IHD was sourced from the Southeast Asian NCD impact module dataset through the WHO-CHOICE OneHealth tool [49] as well as Tang 2007 [38]. The former provided the age specific mortality risk following IHD and the latter provided long term mortality risk, stratified by year. It was assumed after Year 3 patients have same mortality risk as the rest of the "healthy" population.

\section{Cost inputs}

All costs were estimated from a Government perspective in 2019 Vietnamese Dong (VND) at an exchange rate of US\$1 $=23,210 \quad$ [50]. The purchasing power parity (PPP) of 2019 VND from 2015 US\$ was calculated to be 7792 using the CCEMG - EPPI-Centre Cost Converter [50].

Given the Government's minimum involvement in the voluntary strategy, it was assumed no programme implementation costs would be accrued. It is recognised that these costs would be borne by consumers, however this was excluded from the analysis.

Programme costs for the regulatory and subsidised strategies include resources required in the planning, development, and implementation of a population-based health intervention as described by the WHO-CHOICE methodology [49]. This includes the estimated unit price of human resources, training, meetings, supplies, equipment and mass media campaigns (for subsidised strategy only). The resource needs for the regulatory and subsidised interventions were assessed at both a national and provincial level, to reflect regional nuances in cultural and dietary behaviours between provinces. These needs were based on Webb 2017 [26]. Personnel payment norms were based on unified cost norms as issued by United Nations Agencies in Vietnam, European Union (UN-EU) and the Ministry of Planning and Investment of Vietnam [41], inflated to 2019 VND. A per diem daily subsistence allowance of US\$173 for attendees of meetings and training was applied, accounting for a travel allowance [42]. The cost of media and communications for the subsidised scenario was incorporated at both a national and provincial level, based on research by $\mathrm{Ha}$ 2011 [13].

In addition to programme management costs, the cost of a government subsidy for potassium chloride was included in the subsidised strategy. According to the Vietnamese Ministry of Agriculture and Rural Development, Vietnam produces approximately 534,798 $t$ of salt for human consumption each year [40]. Previous research indicated approximately $70 \%$ of salt intake comes from bot canh, fish sauce and salt added when cooking [24]. The literature pertaining to the cost of substituting sodium chloride with potassium chloride is scarce, and as a result, the cost of salt iodisation (\$0.04USD per $\mathrm{kg}$ ) was used as a proxy to estimate the cost of salt reformulation per kilogram [40]. The resulting cost estimate was 1791 per capita, reflecting a proxy for the cost of providing potassium chloride for manufacturers at a similar price to regular salt. As the process of salt substitution 
with potassium chloride is more complex than salt iodisation this assumption is assessed in a sensitivity analysis.

Healthcare costs were derived from Vietnamese specific publications $[45,51]$ with the exception of the cost of acute stroke event which was not available from Vietnamese sources and therefore obtained from a Thai study [44]. To align with incidence data, the cost of IHD was calculated for the acute event, and for the long term recurring cost of chronic treatment post initial health event [45]. There was no long term cost of stroke applied in the model as rehabilitation and long term care is commonly done by family members at home [45].

According to the WHO, the Vietnamese Government pays for approximately $54 \%$ of total healthcare expenditure which was verified by a local source [43]. To reflect a Government perspective, all healthcare costs were calculated accordingly.

\section{Quality of life}

Quality of life values for healthy, post-stroke and postIHD health states were applied in the model, and disutility values for stroke and IHD events were applied at health state transitions.

Quality of life values for the Vietnamese population were gender specific for the whole cohort according to blood pressure status, including patients having "ideal" SBP $(<130 \mathrm{mmHg})$ or Stage $1 \mathrm{SBP}(>130 \mathrm{mmHg}$ ) [46].

The long term stroke utility values were sourced from a UK disease-specific population study of the quality of life of patients post-stroke [48]. The quality of life of patients in the post-IHD health state was calculated using a Vietnamese population specific odds ratio comparing the utility of patients with and without history of previous cerebrovascular event [46], which has previously been used as a proxy for the long term quality of life in patients with stable cardiovascular disease [45].

Disutility values for acute stroke and IHD events were sourced from the Global Burden of Disease study [47]. Disutilities represent the decrement in quality of life due to symptoms or events associated with stroke and IHD events. In the model, disutilities are applied once at the time of the event, as well as a recurring disutility that signifies the long term quality of life lost postacute event. When someone experiences a stroke, their immediate quality of life markedly lowers compared to someone who is healthy, thus they receive a disutility of 0.312 [47]. Similarly for IHD, a person is assigned a one off quality of life decrement of -0.186 when experiencing the acute IHD event [47]. Those who suffer a stroke or IHD event will often experience long term impacts on their quality of life, referred to in the model as the postIHD and post-stroke health states.

\section{Sensitivity and threshold analyses}

A number of one-way sensitivity analyses were run to identify key model drivers and assess any uncertainties. The parameters tested and each upper and lower variable are listed in Table 4.

In addition, the uncertainty surrounding the impact of the individual salt substitution strategies was recognised and tested in a threshold analysis. Specifically, the average salt reduction needed for average costs to equal cost savings was tested at varying time horizons.

\section{Validation}

In order to validate the model results, a comparison was undertaken between the model assumptions and results in relation to previous publications including $\mathrm{Ha} 2011$ [13], Webb 2017 [26] and Cobiac 2010 [18].

\section{Results}

The total cost to implement each of the three salt substitution strategies by year of implementation is shown in Table 5. The cost of the subsidised strategy started at 13 , $678,227,816$ đ (US\$ 589,313) in year 1 , increased to 30 , $539,726,723$ đ (US\$ 1,326,193) in year 2 and decreased to an ongoing cost of $21,808,968,902 ₫$ (US\$ 977,354) for years $6+$. The cost of the regulatory strategy started

Table 4 List of parameter base case values and ranges used in the sensitivity analyses in the cost-effectiveness model

\begin{tabular}{|c|c|c|c|}
\hline Parameter & Lower & Base case & Upper \\
\hline$\%$ Products sodium reduced & $-10 \%$ & & $10 \%$ \\
\hline Discount rate costs & $0 \%$ & $3 \%$ & $5 \%$ \\
\hline Discount rate QALYs & $0 \%$ & $3 \%$ & $5 \%$ \\
\hline Incidence of stroke & $-10 \%$ & & $10 \%$ \\
\hline Stroke RR per $1 \%$ SBP $\Delta$ & $4.0 \%$ & $6.3 \%$ & $8.0 \%$ \\
\hline Incidence of IHD & $-10 \%$ & & $10 \%$ \\
\hline IHD RR per $1 \%$ SBP $\Delta$ & $1.0 \%$ & $3.4 \%$ & $5.0 \%$ \\
\hline Event cost Govt: Stroke & $0 \underline{\Phi}$ & $12,765,544 \underline{\mathrm{d}}$ & $23,596,200 \underline{đ}$ \\
\hline Event cost Govt: IHD & $0 \underline{\Phi}$ & $17,297,680 \underline{đ}$ & $31,973,530 \underline{đ}$ \\
\hline Long term Govt cost: Stroke & $0 \underline{đ}$ & $0 \underline{\ddagger}$ & $25,796,954 \underline{đ}$ \\
\hline Long term Govt cost: IHD & $0 \underline{đ}$ & $368,835 \nsubseteq$ & 681,766 đ \\
\hline Salt substitution cost/kg & US\$ 0.02 & US\$ 0.04 & US\$ 0.08 \\
\hline Cost of healthcare to Govt & $0 \%$ & $54 \%$ & $100 \%$ \\
\hline Cost of project implementation & $-20 \%$ & & $20 \%$ \\
\hline Disutility stroke event & -0.25 & -0.31 & -0.40 \\
\hline Disutility IHD event & -0.10 & -0.19 & -0.28 \\
\hline Utility long term stroke & $-10 \%$ & & $10 \%$ \\
\hline Utility long term IHD & $-10 \%$ & & $10 \%$ \\
\hline Mortality of stroke & $-10 \%$ & 0.37 & $10 \%$ \\
\hline Mortality of IHD & $-10 \%$ & & $10 \%$ \\
\hline
\end{tabular}

Abbreviations: IHD ischaemic heart disease, $Q A L Y_{S}$ quality adjusted life years, SBP systolic blood pressure 
at $12,186,495,637 \nsubseteq$ (US\$ 525,043) in year 1 , increased to $17,311,069,141$ đ (US\$ 751,688) in year 2 and decreased to an ongoing cost of $12,949,953,247$ đ (US\$ 580,410) for years $6+$.

On a yearly basis, the total cost of the voluntary, subsidised and regulatory strategies was estimated to be 0 đ (US\$ 0.00), $536 ₫$ (US\$ 0.02) and $37 \nsubseteq$ (US\$ 0.002) per capita, respectively. However, these costs were offset by healthcare savings due to reduced salt intake and reduced stoke and IHD events. Overall the yearly per capita savings across the three salt substitute scenarios was $49 ₫$ (voluntary; US\$ 0.002), 617 đ (subsidised; US\$ 0.03 ) and $3479 ₫$ (regulatory; US\$ 0.15) (Table 6). Extrapolated to a population level, the yearly cost savings would be between $4775 \mathrm{~m}$ đ (US\$ 205,764) for the voluntary strategy and $337,603 \mathrm{~m}$ đ (US\$ 14,545,300) for the regulatory strategy.

Relative to no intervention, all three of the salt substitution strategies were found to result in less costs and more QALYs gained over a lifetime. Savings and health gains were driven by reductions in stroke and IHD events. Over the model lifetime ( $\sim 70$ years), the voluntary strategy avoided 32,595 and 22,830 stroke and IHD events, respectively. The subsidised strategy avoided 768 , 384 and 537,157 stroke and IHD events respectively, and finally, the regulatory strategy avoided 2,366,480 and 1, 648,590 stroke and IHD events respectively (Table 7).

While all three strategies reduced average government costs, the voluntary salt substitution strategy provided the smallest average cost reduction (3445 đ; US\$ 0.15) and effectiveness benefit (0.009 incremental QALYs gained), as it provided the lowest reduction in dietary sodium intake and thus the lowest reduction in IHD or stroke risk. The subsidised strategy provided an average cost-saving of 43,189đ (US\$ 1.86) and resulted in an average incremental QALY gain of 0.022 . The regulatory strategy provided the highest cost savings (243,530 đ; US\$ 10.49) and incremental QALYs gained (0.074) (Table 7).

As shown in Fig. 2, savings from reduced healthcare offset implementation costs for all three salt substitution strategies. The savings and effectiveness increase when moving from the voluntary strategy to the subsidised strategy to the regulatory strategy due to the increasing population coverage of the reformulated products.

\section{Sensitivity and threshold analyses}

The results of the sensitivity analysis for the voluntary, subsidised and regulatory strategies compared to no intervention are presented in detail in the Supplementary Material (see Supplementary Tables 5-7). Overall, all strategies proved to be robust to all parameter changes, with all three salt substitution strategies remaining dominant (less costly and more effective) for all scenarios with the exception of removing all Government healthcare costs.

Threshold analysis results are presented in Table 8 . For the voluntary strategy the average daily salt reduction required for costs to equal savings was $<0.01 \mathrm{~g}$ at all time horizons. Due to the larger government investment in the subsidised strategy, the average salt reduction for costs to equal savings was $2.17 \mathrm{~g}, 0.27 \mathrm{~g}$ and $0.15 \mathrm{~g}$ at 20 years, 40 years and over a lifetime respectively (the reduction required at 10 years exceed the average daily intake). For the regulatory strategy, the average salt reduction for costs to equal savings was $1.44 \mathrm{~g}, 0.18$ g, $0.05 \mathrm{~g}$ and $0.04 \mathrm{~g}$ at 10 years, 20 years, 40 years and over a lifetime respectively.

\section{Discussion}

The results of this analysis demonstrate the economic impact of three different population level salt substitution strategies. Overall, all strategies are considered costeffective and good value for money from a Vietnam Government perspective. This is due to the low cost of implementing salt substitution strategies at a population level and the considerable costs avoided from initial and long term treatment of stroke and IHD events. Specifically, the annual cost of implementing salt substitution strategies was equal to or less than 536 đ (US\$ 0.02) per captia but led to a reduction of between 32,595 and 2, 366,480 strokes and between 22,830 and 1,648,590 IHD events over the lifetime of the model ( $\sim 70$ years). The reduction in stroke and IHD events led to substantial healthcare savings, making the salt substitution less costs and more effective than the status quo.

The regulatory strategy proved to have the greatest cost-saving, as the Government did not incur the cost of subsidising potassium chloride as well as media and communication costs. The regulatory strategy also provided the greatest quality of life benefit compared to no

Table 5 Total cost of programme implementation phases (per annum) for each salt substitution strategy as estimated through the cost-effectiveness model, Vietnam

\begin{tabular}{|c|c|c|c|}
\hline Phase & Voluntary & Subsidised & Regulatory \\
\hline Planning (Year 1) & $0 \nsubseteq(U S \$ 0)$ & $13,678,227,816 \nsubseteq($ US\$ 589,313) & $12,186,495,637$ đ (US\$ 525,043) \\
\hline Development (Year 2) & $0 \nsubseteq(U S \$ 0)$ & $30,539,726,723 ₫$ (US\$ 1,326,193 & $17,311,069,141 \nsubseteq$ (US\$ 751,688) \\
\hline Partial implementation (Years 3-5) & $0 \nsubseteq(U S \$ 0)$ & $24,336,782,722 ₫($ US\$ 1,073,542) & $12,843,983,050 ₫($ US\$ 566,570) \\
\hline Full implementation (Years 6+) & $0 \nsubseteq(U S \$ 0)$ & 21,808,968,902 đ (US\$ 977,354) & $12,949,953,247 \nsubseteq($ US\$ 580,410) \\
\hline
\end{tabular}


Table 6 Estimated costs accrued with each salt substitution strategy (per capita per annum) from the cost-effectiveness model, Vietnam

\begin{tabular}{|c|c|c|c|c|}
\hline Parameter & No intervention & Voluntary & Subsidised & Regulatory \\
\hline $\begin{array}{l}\text { Average salt substitute strategy costs } \\
\text { per capita per year }\end{array}$ & $0 \nsubseteq$ & $0 \underline{q}$ & $63 ₫$ đ (US\$ 0.002) & $37 \nsubseteq($ US\$ 0.002) \\
\hline $\begin{array}{l}\text { Average salt reformulation cost per } \\
\text { capita per year }\end{array}$ & $0 \nsubseteq$ & $0 \nsubseteq$ & $473 ₫($ US\$ 0.02) & $0 \nsubseteq$ \\
\hline $\begin{array}{l}\text { Average healthcare cost per capita } \\
\text { per year }\end{array}$ & 15,050 đ (US\$ 0.65) & $15,001 \nsubseteq(U S \$ 0.65)$ & 13,896 ₫ (US\$ 0.62) & $11,534 \nsubseteq(U S \$ 0.50)$ \\
\hline $\begin{array}{l}\text { Average total cost per capita per } \\
\text { year }\end{array}$ & 15,050 đ (US\$ 0.65) & 15,001 đ (US\$ 0.65) & 14,433 đ (US\$ 0.62) & 11,571 đ (US\$ 0.50) \\
\hline $\begin{array}{l}\text { Average total incremental cost per } \\
\text { capita per year }\end{array}$ & & -49 đ (US\$ 0.002) & $-617 \mathrm{~d}($ US\$ 0.03) & -3479 đ (US\$ 0.15) \\
\hline $\begin{array}{l}\text { Total incremental savings per } \\
\text { year }^{\mathrm{a}}\end{array}$ & & $4775 m$ d (US\$ 205,764) & $59,873 \mathrm{~m}$ đ (US\$ 2,579,547) & $337,603 \mathrm{~m}$ đ (US\$ 14,545,300) \\
\hline
\end{tabular}

${ }^{\mathrm{a}}$ Assuming population of $97,040,334$

intervention. This is due to the regulatory strategy having the greatest coverage and impact on the target population blood pressure, leading to over $2.3 \mathrm{~m}$ and $1.6 \mathrm{~m}$ stroke and IHD events avoided. Nonetheless, the regulatory strategy would require a concerted policy-making process to implement, including the appropriate planning, implementation, and enforcement legislation. If a less rigorous option is preferred, our analysis also shows the voluntary and subsidised strategies would also provide significant benefits and cost savings to the Vietnam population.

Our results are in line with a recent systematic review of cost-effectiveness publications of different interventions to reduce salt consumption, which found 59 of 62 identified scenarios to be cost-saving [52]. A previous cost-effectiveness analysis of population level interventions aimed at preventing CVD in Vietnam found all programmes to be very cost-effective according to the classification of Commission on Macroeconomics and Health $(\mathrm{CMH})$ on cost-effectiveness [13]. Due to the scarcity of resources available to low and middle income countries such as Vietnam, Ha et al. determined that a health education programme to reduce salt intake and a combined mass media programme on salt, tobacco and cholesterol were the most cost-effective measures [13]. The results of Ha et al. rely on reducing salt consumption through behaviour change whereas our study considers the broader impact of salt substitution policies, demonstrating how various levels of population wide salt reduction interventions are good value for money.

Webb et al. [26] previously studied the cost-effectiveness of implementing a national policy comprising of industry agreement, Government monitoring and public education to decrease sodium intake in 183 nations. The research determined cost-effectiveness of the intervention to be greatest in South Asia, however the study did not take into consideration healthcare costs. For Vietnam, the model estimated 246,143 DALYs averted over 10 years with a cost per capita of US\$ 0.31 . When including healthcare savings from averted stroke and IHD events, our analysis finds such a programme to be even more cost-effective. For the subsidised programme with a 10-year time horizon excluding healthcare costs and with programme implementation costs only shared by those who potentially receive a health benefit from the intervention (i.e. population aged over 25), the cost per capita is approximately US\$ 0.25 .

This analysis has several important limitations. Firstly, we do not have data on the true effect of the salt substitution strategies in Vietnam and therefore all scenarios are hypothetical and may not reflect the final characteristics of voluntary, subsidised and regulatory strategies. This limitation is not unique to our research as previous economic evaluations have all included theoretical

Table 7 Base case cost-effectiveness results of the salt substitution strategies from the cost-effectiveness model, Vietnam

\begin{tabular}{|c|c|c|c|c|c|c|c|}
\hline Strategy & Cost & IncrementalCost & $\begin{array}{l}\text { Strokes } \\
\text { avoided }\end{array}$ & $\begin{array}{l}\text { IHD events } \\
\text { avoided }\end{array}$ & $\begin{array}{l}\text { QALYs } \\
\text { gained }\end{array}$ & $\begin{array}{l}\text { Incremental } \\
\text { Effectiveness }\end{array}$ & ICER \\
\hline No intervention & $1,053,481 \underline{đ}($ US\$ 45.39) & - & - & - & 13.33 & - & - \\
\hline Voluntary & $1,050,036 ₫($ US\$ 45.24) & $-3445 ₫(-U S \$ 0.15)$ & 32,595 & 22,830 & 13.34 & 0.009 & DOMINANT \\
\hline Subsidised & $1,010,292 ₫($ US\$ 43.53) & $-43,189 ₫(-$ US\$ 1.86) & 768,384 & 537,157 & 13.35 & 0.022 & DOMINANT \\
\hline Regulatory & 809,951 đ (US\$ 34.90) & $-243,530 \nsubseteq(-U S \$ 10.49)$ & 236,6480 & $1,648,590$ & 13.41 & 0.074 & DOMINANT \\
\hline
\end{tabular}

Abbreviations: ICER incremental cost-effectiveness ratio, IHD ischaemic heart disease, QALY quality adjusted life year 


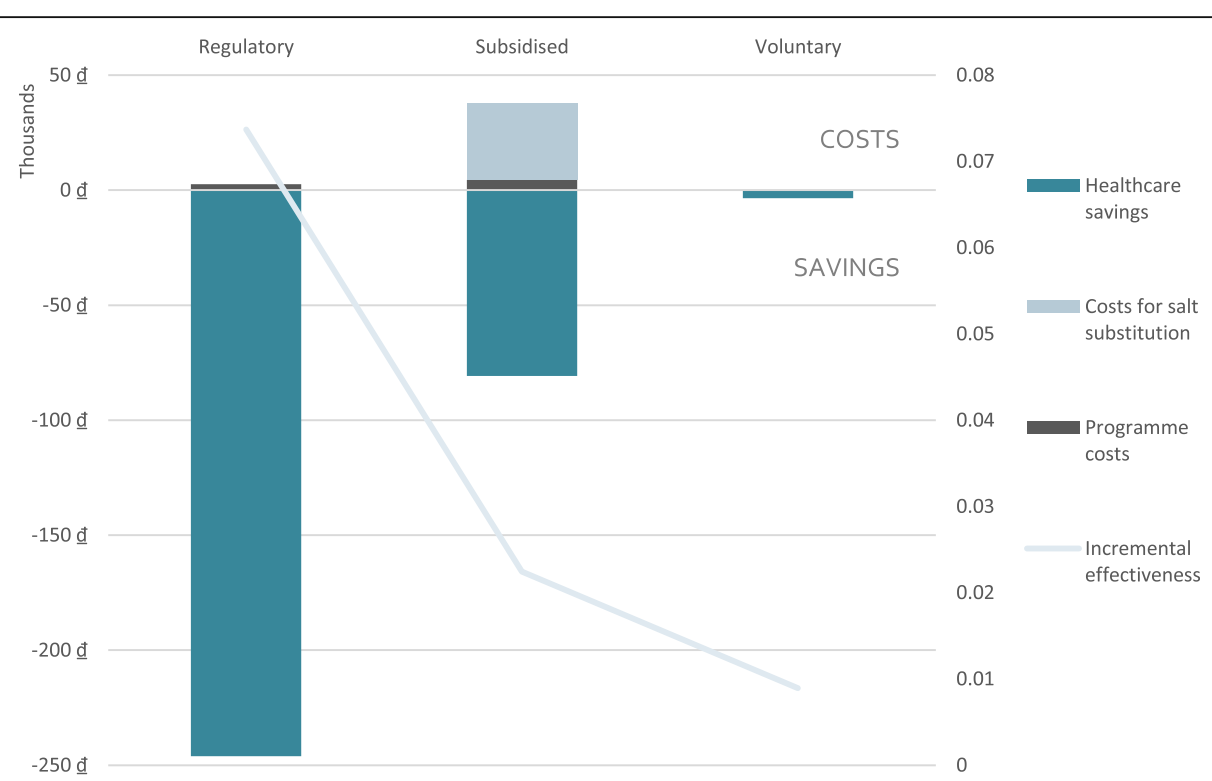

Fig. 2 Average per capita incremental cost and effectiveness of each salt substitute strategy as calculated through the cost-effectiveness model, Vietnam

scenarios and assumptions concerning effectiveness of salt reduction (see Supplementary Material Table 8 for a comparison vs previous literature $[13,18,26])$. To address this, we conducted multiple sensitivity analyses and a threshold analysis to establish a break-even point for each salt substitution strategy. Collectively, these analyses demonstrate that a range of salt substitution strategies are cost-effective and only modest reductions in salt reduction is required at a population level for costs to equal savings.

This analysis was undertaken from the perspective of the Vietnam Government and therefore costs being shifted to industry and consumers are not considered in the analysis. A societal perspective would factor in these initial intervention costs but would to some extent be offset by the savings in out of pocket and private sector costs associated with the prevention of CVD events. The variability in costs of healthcare in Vietnam and the introduction of the universal healthcare scheme also brings uncertainty to the cost of healthcare to the Government. In 2005, the Government on average covered

Table 8 Threshold analyses on average daily salt reduction for costs to equal savings for each salt substitution strategy from the cost-effectiveness model, Vietnam

\begin{tabular}{llll}
\hline Time horizon & Voluntary & Subsidised & Regulatory \\
\hline 10-years & $<0.01 \mathrm{~g}$ & $\mathrm{NA}$ & $1.44 \mathrm{~g}$ \\
20-years & $<0.01 \mathrm{~g}$ & $2.17 \mathrm{~g}$ & $0.18 \mathrm{~g}$ \\
40-years & $<0.01 \mathrm{~g}$ & $0.27 \mathrm{~g}$ & $0.05 \mathrm{~g}$ \\
Lifetime & $0 \mathrm{~g}$ & $0.15 \mathrm{~g}$ & $0.04 \mathrm{~g}$ \\
\hline
\end{tabular}

NA: The salt reduction required for costs to equal savings was greater than the average daily intake approximately $32 \%$ of treatment costs [53], but this has since increased to approximately half and is expected to increase further in the coming years. Taking this into consideration, a sodium reduction programme that reduces stroke and IHD events would be even more costeffective as the government pays an increasingly higher share of the healthcare costs. The cost of care in Vietnam also varies greatly on factors such as geographical location [54], and as the costing studies used in this model are generally from hospitals in major urban cities the cost may not be representative of the true cost of stroke and IHD treatment in non-urban areas in Vietnam.

This model does not take into consideration additional negative health consequences of potassium reformulated salt, for example the risk of hyperkalaemia in people with advanced kidney disease or diabetes [55]. On balance however, the model does not take into consideration the known beneficial effect of potassium on blood pressure in the general population [56] nor does it consider the lowered risk of stomach cancer [57]. Previous research in China showed salt substitution with potassium chloride would potentially cause 11,000 more deaths due to hyperkalaemia but prevent over 460,000 deaths from cardiovascular disease [4]. Therefore, the omission of the negative impact of potassium chloride is unlikely to bias the results.

\section{Conclusion}

This research shows that a range of modelled salt substitution strategies would be cost-effective for the Vietnam Government in lowering SBP at a population level and 
consequently lowering the risk of IHD and stroke. The regulatory intervention provides the most cost-effective option, however, it may not fit within the current government approach or could be met with industry and consumer group opposition. The subsidised alternative would require a higher level of government investment, however the implementation costs will be exceeded by healthcare savings assuming a reasonable time horizon is considered. Considering the high cost of healthcare and the low cost of programme implementation, the Vietnamese Government should strongly consider employing a population level intervention to substitute salt with potassium chloride.

\section{Supplementary Information}

The online version contains supplementary material available at https://doi. org/10.1186/s13690-021-00540-4.

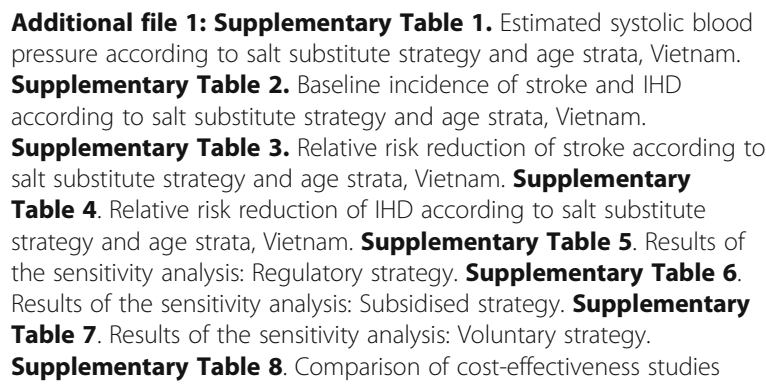

\section{Abbreviations[ \\ CER: Cost-effectiveness ratio; CMH: Commission on Macroeconomics and Health; CVD: Cardiovascular disease; DALY: Disability adjusted life year; GBD: Global Burden of Disease study; ICER: Incremental cost-effectiveness ra- tio; IHD: Ischaemic heart disease; MBS: Medicare Benefits Schedule; NCD : Non communicable disease; PBS: Pharmaceutical Benefits Schedule; PPP: Purchasing power parity; QALY: Quality adjusted life year; RR: Relative risk; SBP: Systolic blood pressure; UN-EU: United Nations Agencies in Vietnam, European Union; VND: Vietnamese Dong; WHO: World Health Organisation}

\section{Acknowledgements}

Not applicable

\section{Authors' contributions}

ID and AP designed and conducted the analyses contained in this report. JW and HDP provided advice on model inputs. CT wrote the manuscript. All authors reviewed and commented on drafts and agreed the final draft.

\section{Funding}

This project was funded by Vital Strategies as part of a Resolve to Save Lives Sodium Reduction LINKS grant. JW is supported by a National Heart Foundation of Australia Future Leaders Fellowship Level II \#102039. KT was supported by an Early Career Fellowship (APP1161597) from the National Health and Medical Research Council of Australia (NHMRC) and a Postdoctoral Fellowship (Award ID 102140) from the National Heart Foundation of Australia.

\section{Availability of data and materials}

The datasets used and/or analysed during the current study are available from the corresponding author on reasonable request.

Ethics approval and consent to participate Not applicable.
Consent for publication

Not applicable.

\section{Competing interests}

CT is part owner of a company Health Technology Analysts Pty Ltd. (HTAnalysts) which undertakes paid health economics consultancy work for industry and Government. ID and AP are employees of HTAnalysts. HTAnalysts received remuneration to undertake analyses contained in this manuscript. However no remuneration was received in relation to the development of this manuscript.

\section{Author details}

${ }^{1}$ The George Institute for Global Health, Australia University of NSW, PO Box M201, Missenden Rd, Camperdown, NSW 2050, Australia. ${ }^{2}$ Health Technology Analysts Pty Ltd, Surry Hills, Australia. ${ }^{3}$ National Institute of Nutrition, Hanoi, Viet Nam. ${ }^{4}$ YCP Solidiance Company Ltd, Hanoi, Viet Nam. ${ }^{5}$ Resolve to Save Lives, An Initiative of Vital Strategies, New York, NY, USA.

Received: 7 October 2020 Accepted: 7 February 2021

Published online: 11 March 2021

\section{References}

1. Roth GA, et al. Global, regional, and National Burden of cardiovascular diseases for 10 causes, 1990 to 2015. J Am Coll Cardiol. 2017;70(1):1-25.

2. Naghavi $\mathrm{M}$, et al. Global, regional, and national age-sex specific mortality for 264 causes of death, 1980-2016: a systematic analysis for the global burden of disease study 2016. Lancet. 2017;390(10100):1151-210.

3. World Health Organisation. Cardiovascular disease fact sheet: WHO; 2017.

4. Marklund $\mathrm{M}$, et al. Estimated population wide benefits and risks in China of lowering sodium through potassium enriched salt substitution: modelling study. BMJ. 2020;m824:369

5. Lackland DT, Weber MA. Global burden of cardiovascular disease and stroke: hypertension at the core. Can J Cardiol. 2015;31(5):569-71.

6. Pickering TG. The natural history of hypertension: prehypertension or masked hypertension? J Clin Hypertens. 2007;9(10):807-10.

7. World Health Organisation. Sodium intake for adults and children. In: eLibrary of Evidence for Nutrition Actions (eLENA); 2020.

8. World Health Organisation. Global Action Plan for the Prevention and Control of Noncommunicable Diseases 2013-2020. Geneva: WHO; 2013.

9. Murray CJ, et al. Effectiveness and costs of interventions to lower systolic blood pressure and cholesterol: a global and regional analysis on reduction of cardiovascular-disease risk. Lancet. 2003;361(9359):717-25.

10. Joffres MR, et al. Estimate of the benefits of a population-based reduction in dietary sodium additives on hypertension and its related health care costs in Canada. Can J Cardiol. 2007;23(6):437-43.

11. Bibbins-Domingo $K$, et al. Projected effect of dietary salt reductions on future cardiovascular disease. N Engl J Med. 2010;362(7):590-9.

12. Smith-Spangler $\mathrm{CM}$, et al. Population strategies to decrease sodium intake and the burden of cardiovascular disease: a cost-effectiveness analysis. Ann Intern Med. 2010;152(8):481-7 w170-3.

13. Ha DA, Chisholm D. Cost-effectiveness analysis of interventions to prevent cardiovascular disease in Vietnam. Health Policy Plan. 2011;26(3):210-22.

14. Martikainen JA, et al. Health economic consequences of reducing salt intake and replacing saturated fat with polyunsaturated fat in the adult Finnish population: estimates based on the FINRISK and FINDIET studies. Eur J Clin Nutr. 2011;65(10):1148-55.

15. Wang G, Bowman BA. Recent economic evaluations of interventions to prevent cardiovascular disease by reducing sodium intake. Curr Atheroscler Rep. 2013;15(9):349.

16. Mason $\mathrm{H}$, et al. A cost effectiveness analysis of salt reduction policies to reduce coronary heart disease in four eastern Mediterranean countries. PLoS One. 2014;9(1):e84445.

17. Cobiac $\sqcup$, et al. Which interventions offer best value for money in primary prevention of cardiovascular disease? PLoS One. 2012;7(7):e41842.

18. Cobiac $\amalg$, Vos $T$, Veerman $J$. Cost-effectiveness of interventions to reduce dietary salt intake. Heart. 2010;96(23):1920-5.

19. World Health Organisation. In: Alwan A, editor. Global status report on noncommunicable diseases 2010. Geneva: WHO; 2011.

20. Ibrahim MM, Damasceno A. Hypertension in developing countries. Lancet. 2012;380(9841):611-9. 
21. World Health Organisation. Noncommunicable diseases country profiles. Geneva: WHO; 2014.

22. Khan NC, Khoi HH. Double burden of malnutrition: the Vietnamese perspective. Asia Pac J Clin Nutr. 2008;17(Suppl 1):116-8.

23. General Department of Preventive Medicine, V. National survey on the risk factors of non-communicable diseases (STEPS). Hanoi: Ministry of Health; 2016.

24. Do HT. Hypertension in Vietnam: prevalence, risk groups and eff ects of salt substitution. Wageningen: Wageningen University; 2014.

25. Peng YG, et al. Effects of salt substitutes on blood pressure: a meta-analysis of randomized controlled trials. Am J Clin Nutr. 2014;100(6):1448-54.

26. Webb M, et al. Cost effectiveness of a government supported policy strategy to decrease sodium intake: global analysis across 183 nations. BMJ. 2017;i6699:356.

27. Hope SF, et al. A systematic review of economic evaluations of populationbased sodium reduction interventions. PLoS One. 2017;12(3):e0173600.

28. Solidiance YCP. Market Feasibility Assessment for Low-sodium Salt, Fish sauce, Bot canh, and Bot nem for Vietnam. Ho Chi Minh City: YCP Solidiance; 2020

29. Gillespie DO, et al. The health equity and effectiveness of policy options to reduce dietary salt intake in England: policy forecast. PLoS One. 2015;10(7): e0127927.

30. HTP D. Hypertension in Vietnam: prevalence, risk groups and effects of salt substitution: Wageningen University; 2014.

31. Do HT, et al. Effectiveness of a communication for behavioral impact (COMBI) intervention to reduce salt intake in a Vietnamese Province based on estimations from spot urine samples. J Clin Hypertens (Greenwich). 2016; 18(11):1135-42.

32. Codling K. Salt iodisation in Vietnam: learning from the past and building Back better, UNICEF; 2013.

33. Khai G, Viet L, Son T. Epidemiological survey of hypertension and its risk factors in Vietnam. Hanoi: Presentation at the World Health Organization's office; 2008

34. Law MR, Frost CD, Wald NJ. Dietary salt and blood pressure. J Hypertens Suppl. 1991;9(6):S37-41 discussion S47-9.

35. Global Health Observatory. Vietnam Life Tables: W.H. Organisation; 2019.

36. Tirschwell $\mathrm{DL}$, et al. A prospective cohort study of stroke characteristics, care, and mortality in a hospital stroke registry in Vietnam. BMC Neurol. 2012;12:150.

37. Kiyohara $Y$, et al. Ten-year prognosis of stroke and risk factors for death in a Japanese community: the Hisayama study. Stroke. 2003;34(10):2343-7.

38. Tang EW, Wong CK, Herbison P. Global registry of acute coronary events (GRACE) hospital discharge risk score accurately predicts long-term mortality post acute coronary syndrome. Am Heart J. 2007;153(1):29-35.

39. The Ministry of Agriculture and Rural Development. Report of manufacturing and business performance in November 2018 - Agriculture and rural development sector. Vietnam: The Ministry of Agriculture and Rural Development; 2018.

40. Thai Nguyen Province People's Committee. Approval of the plan, subsidy schemes, supply and pricing strategy for iodised salt to prevent goiter in local ethnic minorities living in mountainous areas in Thai Nguyen province in 2018. Vietnam: Thai Nguyen Province People's Committee; 2018.

41. Chi Dzung N, Mehta P, Jessen F. UN-EU Guidelines for Financing of Local Costs in Development Co-Operation with Viet Nam. Ha Noi: Ministry of Planning and Investment of Vietnam, United Nations, European Union; 2015.

42. Bertram MY, et al. Disease control programme support costs: an update of WHO-CHOICE methodology, price databases and quantity assumptions. Cost Effectiveness Resour Allocation. 2017;15(1):21.

43. World Health Organisation, UHC and SDG Country Profile 2018: Viet Nam. Geneva: WHO; 2018.

44. Khiaocharoen O, Pannarunothai S, Zungsontiporn C. Cost of acute and subacute care for stroke patients. J Med Assoc Thail. 2012;95(10):1266-77.

45. Nguyen TP, et al. Cost-effectiveness analysis of screening for and managing identified hypertension for cardiovascular disease prevention in Vietnam. PLoS One. 2016;11(5):e0155699.

46. Nguyen T-P-L, et al. Utilities of Patients with hypertension in northern Vietnam. PLoS One. 2015;10(10):e0139560.

47. Salomon JA, et al. Common values in assessing health outcomes from disease and injury: disability weights measurement study for the global burden of disease study 2010. Lancet. 2012;380(9859):2129-43.
48. Luengo-Fernandez R, et al. Quality of life after TIA and stroke: ten-year results of the Oxford vascular study. Neurology. 2013;81(18):1588-95.

49. World Health, O. OneHealth Tool: Supporting integrated strategic health planning, costing and health impact analysis. WHO-CHOICE (costeffectiveness and strategic planning). 2013. [22/05/2020]; Available from: https://www.who.int/choice/onehealthtool/en/.

50. Campbell Collaboration. EPPI-Centre Cost Converter. 2020. [cited 2020 February]; Available from: https://eppi.ioe.ac.uk/costconversion/default.aspx.

51. Vo TQ, Le PH. Post-stroke rehabilitation cost with traditional therapy: Evidence from a public hospital. J Pak Med Assoc. 2019;69((Suppl 2)(6)):S87s95.

52. Schorling E, Niebuhr D, Kroke A. Cost-effectiveness of salt reduction to prevent hypertension and CVD: a systematic review. Public Health Nutr. 2017;20(11):1993-2003.

53. Lieberman SS, Wagstaff A. Health financing and delivery in Vietnam: looking forward: World Bank Publications; 2009.

54. Nguyen HM. Inequality in healthcare costs between residing and nonresiding patients: evidence from Vietnam. Int J Equity Health. 2017;16(1):76.

55. Watanabe R. Hyperkalemia in chronic kidney disease. Rev Assoc Med Bras. 1992;66(Suppl 1):s31-6.

56. Smith SR, Klotman PE, Svetkey LP. Potassium chloride lowers blood pressure and causes natriuresis in older patients with hypertension. J Am Soc Nephrol. 1992;2(8):1302-9.

57. Tsugane S. Salt, salted food intake, and risk of gastric cancer: epidemiologic evidence. Cancer Sci. 2005;96(1):1-6.

\section{Publisher's Note}

Springer Nature remains neutral with regard to jurisdictional claims in published maps and institutional affiliations.
Ready to submit your research? Choose BMC and benefit from:

- fast, convenient online submission

- thorough peer review by experienced researchers in your field

- rapid publication on acceptance

- support for research data, including large and complex data types

- gold Open Access which fosters wider collaboration and increased citations

- maximum visibility for your research: over $100 \mathrm{M}$ website views per year

At BMC, research is always in progress.

Learn more biomedcentral.com/submissions 